\title{
MEDIA PEMBELAJARAN JENIS-JENIS KAKTUS DENGAN PENERAPAN MARKER BASED TRACKING AUGMENTED REALITY
}

\author{
ACHMAD ADITYA ASHADUL USHUD \\ Universitas Budi Luhur \\ e-mail : achmad.aditya@budiluhur.ac.id
}

\begin{abstract}
Cactus is known as a thorny plant that lives in less water conditions because it can save water inside its trunk. Most people know cactus as a thorny plant, even though not all cacti have thorns. This is because many people do not know the types of cactus. Especially at this time, many cacti used as houseplants. Because there are several types of cactus have a beautiful shape, besides that the cactus is also known to be easily treated because it does not need to be watered frequently. This study aims to recognize and identify the types of cacti in the world through an interactive learning media that is easy to do, namely Augmented Reality. During this time many cactus were introduced only through books, pictures or photos. Meanwhile, to present the cactus itself is difficult. Especially for some types of cactus that live in certain areas and including rare. So to recognize the cactus in detail is felt difficult to do. By using Augmented Reality technology with Marker Based Tracking method based on Android phone, it is hoped that it can help the learning process. Users can identify the types of cactus through the mobile screen.
\end{abstract}

Key Words : Augmented Reality, Marker Based Tracking, cactus, Android

\section{ABSTRAK}

Kaktus dikenal sebagai tanaman berduri yang hidup pada kondisi sedikit air karena kaktus dapat menyimpan air pada batangnya. Kebanyakan orang mengenal kaktus sebagai tumbuhan berduri, padahal tidak semua kaktus mempunyai duri. Hal ini karena banyak orang tidak mengenal jenis-jenis kaktus. Apalagi saat ini kaktus banyak dijadikan tanaman hias. Karena ada beberapa jenis kaktus memiliki bentuk yang indah, selain itu kaktus juga dikenal mudah dirawat karena tidak perlu sering-sering disiram. Penelitian ini bertujuan untuk mengenal dan mengidentifikasi jenis-jenis kaktus yang ada di dunia ini melalui media pembelajaran interaktif yang mudah dilakukan, yaitu Augmented Reality. Selama ini kaktus banyak dikenalkan hanya melalui buku, gambar atau foto. Sementara untuk menghadirkan kaktus sendiri merupakan hal yang sulit. Apalagi untuk sebagian jenis kaktus yang hidup di daerah tertentu dan termasuk langka. Sehingga untuk mengenali kaktus secara detail dirasakan sulit dilakukan. Melalui teknologi Augmented Reality dengan metode Marker Based Tracking dalam bentuk aplikasi pada handphone Android ini, diharapkan dapat membantu dalam proses pembelajaran jenisjenis kaktus menjadi lebih mudah. Pengguna dapat mengidentifikasi jenis-jenis kaktus melalui layar handphone.

Kata Kunci: Augmented Reality, Marker Based Tracking, Kaktus, Android 


\section{PENDAHULUAN}

\section{Latar Belakang}

Media pembelajaran yang selama ini banyak digunakan adalah media cetak seperti buku. Setelah itu media audio visual mulai digunakan untuk membantu memahami materi agar lebih mudah. Dalam hal mengamati objek, seringkali untuk mendapatkan informasi tentang objek tersebut, dibutuhkan untuk melihat langsung objek yang diamati, bukan hanya melihat melalui gambar atau foto yang ada di dalam buku. Saat ini ada teknologi yang memungkinkan menghadirkan obyek yang ingin diamati secara langsung melalui media digital. Teknologi tersebut adalah Augmented Reality (AR). Teknologi Augmented Reality secara langsung dapat mewujudkan dunia maya ke dalam dunia nyata, dalam bentuk 3 dimensi sehingga sangat membantu proses belajar agar tidak monoton [1]. AR ini disebut juga sebagai realitas tambahan yang merupakan penggabungan objek digital dua atau tiga dimensi dari dunia maya ke dalam lingkungan yang ada di dunia nyata yang dapat dilakukan secara real time [2].

Kaktus yang ada di dunia memiliki berbagai jenis. Untuk mengenali jenis-jenis kaktus tidaklah mudah. Terutama bagi orang biasa yang hanya bisa mengenali kaktus karena tumbuhan tersebut berduri dan punya batang besar berwarna hijau. Padahal tidak semua jenis kaktus memilki duri. Mengenali jenis kaktus tentunya akan sulit jika hanya mengandalkan gambar atau foto, karena seringkali gambar atau foto tidak merepresentasikan bentuk kaktus seutuhnya.

Penelitian ini bertujuan untuk mempermudah dalam mengenali jenis kaktus menggunakan teknologi Augmented Reality dengan metode Marker Based Tracking sebagai pembelajaran. Penelitian ini menghasilkan sebuah aplikasi yang dapat menampilkan tanaman kaktus tersebut dalam bentuk 3D objek. Ada tiga tujuan pembelajaran yang perlu diperhatikan dalam menampilkan objek ke bentuk 3 dimensi diantaranya [3]:

1. Objek dapat dikenali dengan mudah.

2. Objek dapat dikenali melalui petunjuk, berupa suara misalnya.

3. Tampilan 3 dimensi sesuai dengan objek yang dipilih.
TINJAUAN PUSTAKA

\section{Hasil Penelitian Sebelumnya}

Penelitian yang telah dilakukan oleh Julia Safitri dan tim, telah membuat aplikasi yang mampu membantu proses belajar mengajar bagi para para guru di sekolah dasar sehingga lebih interaktif dan meningkatkan minat belajar siswa. Selain itu aplikasi juga mampu membantu mengidentifikasi perbedaan tanaman dikotil dan monokotil dengan lebih mudah [4].

Penelitian yang telah dilakukan oleh Dedy Atmajaya menghasilkan aplikasi interaktif menggunakan teknologi Augmented Reality untuk meningkatkan minat belajar siswa PAUD yang sering sekali terganggu focus dan konsentrasinya. Dengan pembelajaran interaktif ini, para guru sangat terbantu untuk mendapatkan perhatian dari siswa sekaligus proses pengajaran menjadi lebih menarik [3].

\section{Kaktus}

Saat ini banyak orang yang menggemari tanaman kaktus untuk dijadikan tanaman hias yang ditempatkan di dalam rumah. Alasan menjadikan kaktus sebagai tanaman hias adalah karena keunikan bentuk pada kaktus. Bentuk kaktus yang unik ini dianggap berfungsi sebagai pemanis ruangan. Selain itu perawatan tanaman kaktus tidak sulit, kaktus cukup ditempatkan di tempat yang mendapatkan sinar matahari yang cukup, dan hanya perlu disiram satu atau dua pekan sekali.

\section{Augmented Reality}

Multimedia telah lama digunakan sebagai media pembelajaran yang efektif. Multimedia menggabungkan berbagai bentuk sarana seperti teks, suara, gambar, video dan sebagainya dalam bentuk digital sehingga dapat dissampaikan melalui media seperti komputer untuk dapat dibuat secara interaktif. [5]. Augmented Reality dirasakan lebih efektif dalam menyampaikan informasi, terutama dalam kegiatan belajar dan mengajar dibandingkan dengan media pembelajaran lainnya [6]. Dalam Augmented Reality, ada beberapa metode yang digunakan, yaitu marker based tracking dan markerless [7]. 
1. Marker based tracking.

Marker based tracking menggunakan marker atau penanda berupa objek dua dimensi yang memiliki suatu pola biasanya merupakan ilustrasi hitam dan putih.

2. Markerless:

Marker dikenali dalam bentuk posisi perangkat, arah, atau lokasi. Sehingga dengan metode markerless pengguna tidak perlu lagi mencetak sebuah marker.

Penelitian ini menggunakan metode marker based tracking, dimana marker dibuat dan siapkan terlebih dahulu. Marker harus dapat dikenali dengan mudah oleh system AR. Sehingga marker dapat dikatakan harus reliable pada segala kondisi [8].

\section{METODE}

Metode penelitian yang digunakan dalam pembuatan media pembelajaran ini memiliki 4 tahapan proses. Pada tahap pertama, dilakukan perencanaan, studi literatur, perumusan masalah dan solusi yang diterapkan. Tahap kedua adalah pengumpulan data, melalui observasi, wawancara, dan survei. Lalu data yang didapatkan diolah dan didokumentasikan. Tahap ketiga adalah mulai analisa dan pembuatan sistem, termasuk di dalamnya uji coba dan revisi. Tahap terakhir adalah evaluasi.

\section{Flowchart Sistem}

Berdasarkan hasil analisa, dibuatlah flowchart sistem untuk menggambarkan lebih rinci alur proses atau langkah prosedur program. DImana program dimulai dengan menampilkan menu utama kepada pengguna. Pilihan menu tersebut adalah mulai mendeteksi marker atau mulai mengidentifikasi tanaman kaktus, menampilkan panduan penggunaan program dalam menu tentang, dan keluar.

Menu dibuat sederhana dengan tujuan mudah dipahami dan dapat langsung digunakan. Gambar flowchart ditunjukkan pada gambar 1 di bawah.

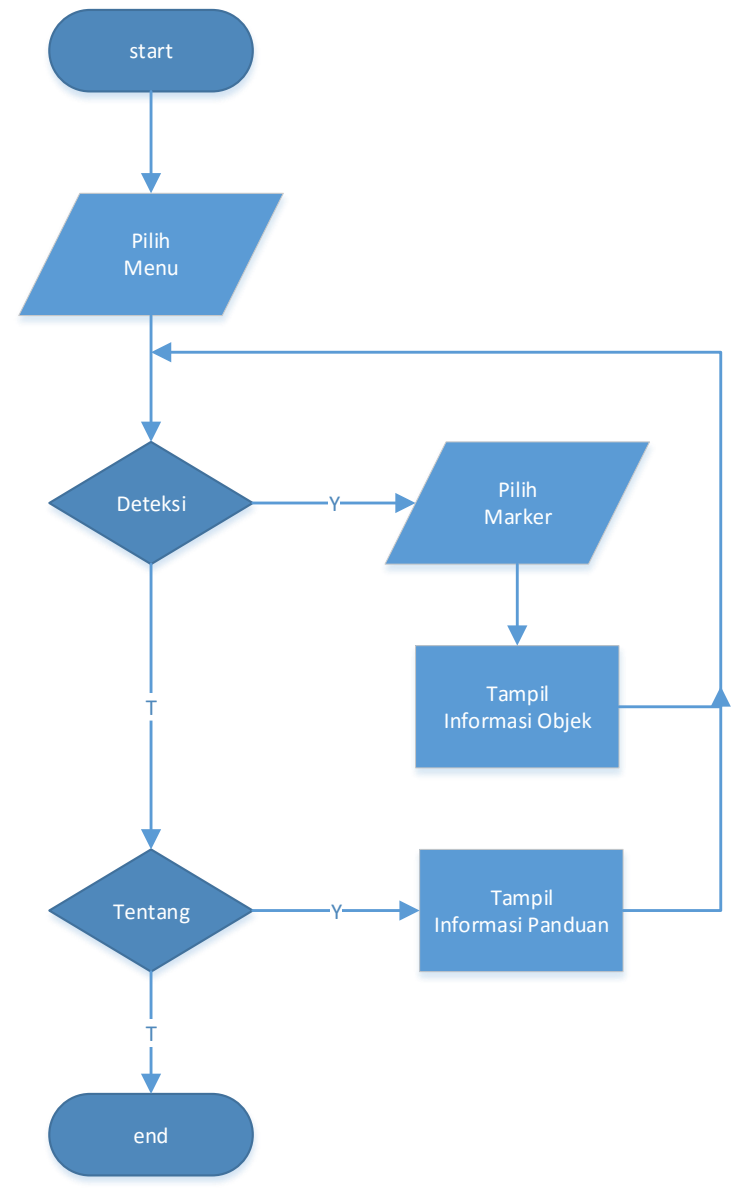

Gambar 1. Flowchart Sistem

\section{Analisa Kebutuhan Perangkat Lunak}

Spesifikasi kebutuhan perangkat keras (hardware) dan perangkat lunak (software) agar aplikasi ini dapat berjalan dengan baik adalah sebagai berikut.

1. Perangkat Laptop yang digunakan dalam membuat aplikasi adalah:

a. RAM 8 GB DDR 4

b. Prosesor Intel Core i5-6200 4 CPU $2,3 \mathrm{GHz}$

c. Hardisk SSD $250 \mathrm{~GB}$

d. VGA Card NVidia GeForce 940MX 4GB 
2. Perangkat Smartphone yang digunakan dalam menjalankan aplikasi yang telah dibuat adalah:
a. Sistem Operasi Android 9 Oreo
b. Processor Snapdragon 625 Octa Core Cortex A53 $2 \mathrm{Ghz}$
c. RAM 4 GB
d. Kamera $12 \mathrm{MP}$
e. Resolusi 1920 x 1080 piksel

\section{Desain}

\section{Rancangan Menu}

Menu awal ketika aplikasi ini dijalankan adalah, Deteksi, Panduan dan Keluar. Menu Deteksi akan memulai mendeteksi marker, menu Panduan menampilkan informasi panduan penggunaan aplikasi. Sedang menu Keluar akan menutup aplikasi.

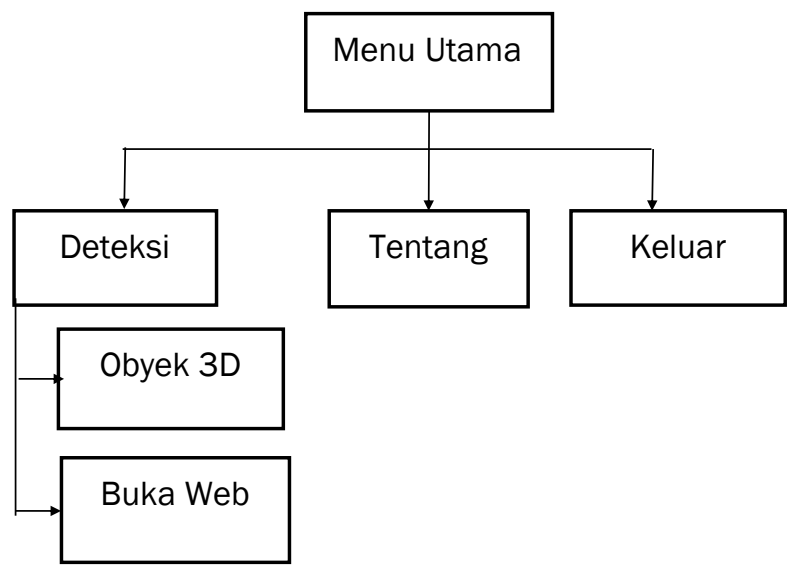

Gambar 2. Rancangan Menu

\section{Rancangan Layar Aplikasi}

Rancangan layar aplikasi merupakan bentuk tampilan dari aplikasi yang dibuat untuk memberikan informasi bagi pengguna dalam menggunakannya.

a. Rancangan Layar Menu Utama

Rancangan layar menu utama merupakan tampilan awal aplikasi.

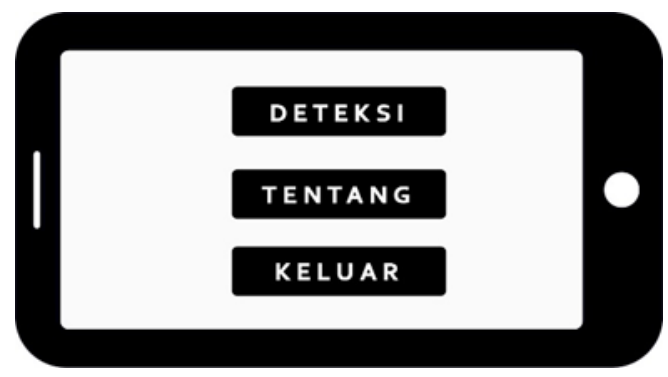

Gambar 3. Rancangan Layar Menu Utama b. Rancangan Layar Deteksi

Rancangan layar deteksi ini pengguna dapat memilih marker yang akan diidentifikasi agar objek 3D dan informasi dapat muncul pada layar smartphone. Pada menu ini terdapat tombol kembali yang saat ditekan akan pindah ke layar menu utama.

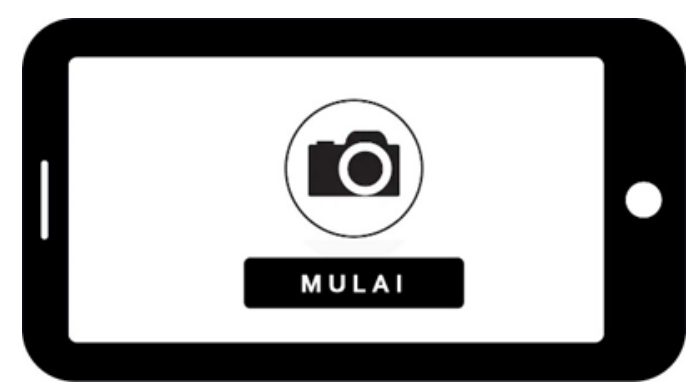

Gambar 4. Rancangan Layar Deteksi

C. Rancangan Layar Tentang

Pada rancangan layar tentang berisi informasi mengenai cara penggunaan dari aplikasi ini.

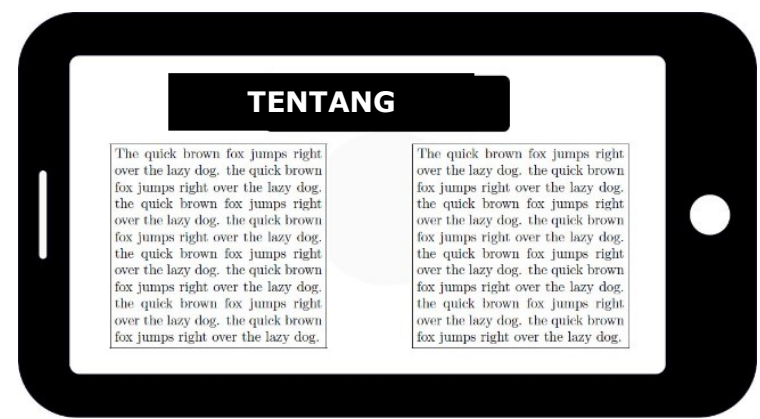

Gambar 5. Rancangan Layar Tentang

\section{HASIL DAN PEMBAHASAN}

\section{Implementasi}

Pengujian aplikasi dilakukan untuk mengetahui apakah semuai fungsi yang ada pada aplikasi telah berjalan dengan baik dan sesuai kebutuhan.

1. Implementasi Tampilan Layar Menu Utama Tampilan layar menu utama akan muncul dan terdapat menu seperti Deteksi, Tentang, dan Keluar.

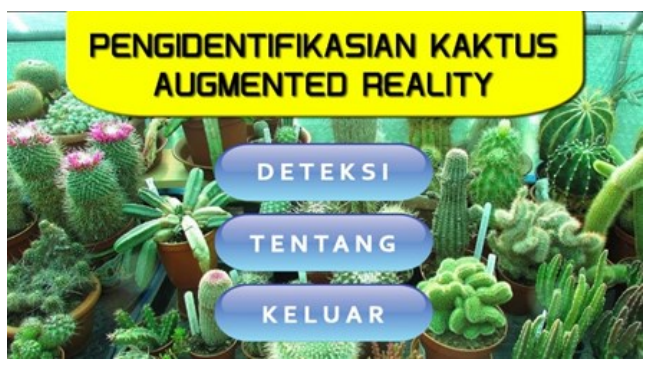

Gambar 6. Tampilan Layar Menu Utama 
2. Implementasi Tampilan Deteksi

Tampilan layar ini berfungsi untuk mendeteksi marker yang akan di-scan dan menampilkan objek 3D.

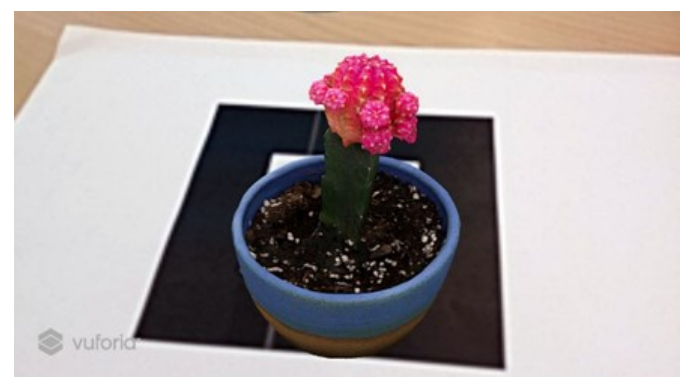

Gambar 7. Tampilan Deteksi

3. Implementasi Tampilan Tentang

Tampilan ini berisi petunjuk penggunaan dari aplikasi tersebut.

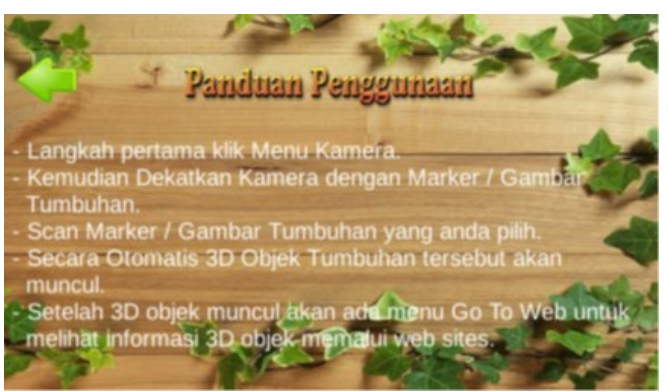

Gambar 8. Tampilan Tentang

\section{Pengujian}

Pengujian dilakukan menggunakan metode black box testing. Bertujuan untuk menemukan kesalahan fungsi pada aplikasi. Berikut adalah pengujian black box testing pada aplikasi ini.

1. Pengujian Layar Menu Utama

Berikut tabel pengujian menu utama.

Tabel 1. Pengujian menu utama

\begin{tabular}{|c|l|l|l|l|}
\hline No & Pengujian & $\begin{array}{c}\text { Yang } \\
\text { diharapkan }\end{array}$ & Hasil & Kesimpulan \\
\hline 1 & $\begin{array}{l}\text { Plih Menu } \\
\text { Deteksi }\end{array}$ & $\begin{array}{l}\text { Layar berpin- } \\
\text { dah ke layar } \\
\text { AR Kamera }\end{array}$ & $\begin{array}{l}\text { Menu } \\
\text { Deteksi } \\
\text { berfungsi }\end{array}$ & Berhasil \\
\hline 2 & $\begin{array}{l}\text { Pilih Menu } \\
\text { Tentang }\end{array}$ & $\begin{array}{l}\text { Layar } \\
\text { berpindah ke } \\
\text { layar Tentang }\end{array}$ & $\begin{array}{l}\text { Menu } \\
\text { Tentang } \\
\text { berfungsi }\end{array}$ & Berhasil \\
\hline 3 & $\begin{array}{l}\text { Klik Menu } \\
\text { Keluar }\end{array}$ & $\begin{array}{l}\text { Aplikasi } \\
\text { tertutup }\end{array}$ & $\begin{array}{l}\text { Menu } \\
\text { Keluar } \\
\text { berfungsi }\end{array}$ & Berhasil \\
\hline
\end{tabular}

2 Pengujian Layar Menu Deteksi

Berikut tabel pengujian layar deteksi.

Tabel 2. Pengujian layar deteksi

\begin{tabular}{|c|l|l|l|l|}
\hline No & Pengujian & $\begin{array}{c}\text { Yang } \\
\text { Diharapkan }\end{array}$ & Hasil & Kesimpulan \\
\hline 1 & $\begin{array}{l}\text { Kamera } \\
\text { mengarah } \\
\text { ke marker }\end{array}$ & $\begin{array}{l}\text { Menampil- } \\
\text { kan objek } \\
\text { virtual 3D } \\
\text { yang telah } \\
\text { dibuat }\end{array}$ & $\begin{array}{l}\text { Muncul } \\
\text { objek beru- } \\
\text { pa sebuah } \\
\text { tanaman } \\
\text { kaktus }\end{array}$ & Berhasil \\
\hline 2 & $\begin{array}{l}\text { Pilih menu } \\
\text { Kembali }\end{array}$ & $\begin{array}{l}\text { Kembali ke } \\
\text { Menu } \\
\text { Utama }\end{array}$ & $\begin{array}{l}\text { Menu } \\
\text { Kembali } \\
\text { berfungsi }\end{array}$ & Berhasil \\
\hline
\end{tabular}

3. Pengujian Layar Tentang

Berikut tabel pengujian tentang.

Tabel 3. Pengujian layar tentang

\begin{tabular}{|c|l|l|l|c|}
\hline No & Pengujian & $\begin{array}{c}\text { Yang } \\
\text { Diharapkan }\end{array}$ & Hasil & Kesimpulan \\
\hline 1 & $\begin{array}{l}\text { Pilih menu } \\
\text { Tentang }\end{array}$ & $\begin{array}{l}\text { Menampilka } \\
\text { n Informasi }\end{array}$ & $\begin{array}{l}\text { Tampil } \\
\text { informasi } \\
\text { panduan } \\
\text { penggunaan }\end{array}$ & Berhasil \\
\hline 2 & $\begin{array}{l}\text { Pilih menu } \\
\text { Kembali }\end{array}$ & $\begin{array}{l}\text { Kembali ke } \\
\text { Menu Utama }\end{array}$ & $\begin{array}{l}\text { Menu } \\
\text { Kembali } \\
\text { berfungsi }\end{array}$ & Berhasil \\
\hline
\end{tabular}

\section{KESIMPULAN}

Berdasarkan hasil perancangan dan analisa program pada aplikasi ini, dapat diambil beberapa kesimpulan antara lain.

1. Dengan menggunakan teknologi Augmented Reality proses pengidentifikasian tanaman kaktus tidak perlu menghadirkan tanaman tersebut secara fisik.

2. Teknologi Augmented Reality membantu pengguna dalam proses identifikasi jenis-jenis kaktus.

3. Teknologi Augmented Reality terbukti mudah digunakan dan diaplikasikan, karena saat ini pengguna sudah terbiasa dengan penggunaan smartphone dan kameranya, sehingga penggunaan teknologi Augmented Reality sudah tidak asing lagi. 


\section{DAFTAR PUSTAKA}

[1] R. E. Saputro dan D. I. S. Saputra, "Pengembangan Media Pembelajaran Mengenal Organ Pencernaan," Buana Informatika, vol. 6, no. 2 April, pp. 153-162, 2015.

[2] A. R. Yudiantika, E. Pasinggi, I. P. Sari dan B. S. Hantono, "Implementasi Augmented Reality di Museum: Studi Awal Perancangan," PaperKNASTIK, 2013.

[3] D. Atmajaya, "Implementasi Augmented Reality untuk Pembelajaran Interaktif," ILKOM Jurnal IImiah, vol. 9, no. 2 Agustus, pp. 227-232, 2017.

[4] J. Safitri, P. Meilina dan S. N. Ambo, "Implementasi Augmented Reality Sebagai Pembelajaran Pertumbuhan Tanaman Dikotil Dan Monokotil Untuk Sekolah Dasar," JUST IT, vol. 9, no. 1, pp. 32-38, 2018.
[5] I. Binanto, Multimedia Digital-Dasar Teori dan Pengembangannya., Yogyakarta: Andi, 2010.

[6] I. Radu, "Why should my students use AR? A comparative review of the educational impacts of Augmented-Reality," IEEE International Symposium, pp. 313-314, 2012.

[7] A. Rahman, E. dan F. F. Coastera, "Rancang Bangun Aplikasi Informasi Universitas Bengkulu sebagai Panduan Pengenalan Kampus Menggunakan Metode Markerless Augmented Reality Berbasis android," Rekursif, vol. 2, no. 2 November, pp. 63-71, 2014.

[8] S. SIltanen, Theory and Applications of MarkerBased Augmented Reality, vol. 3, Finland: VTT, 2012. 